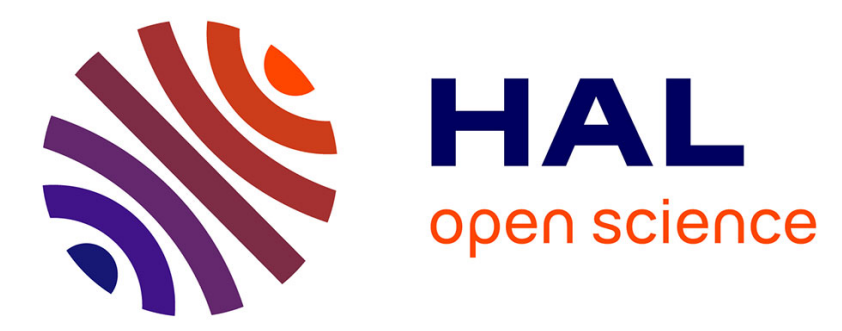

\title{
Microtubule-associated tumor suppressors as prognostic biomarkers in breast cancer
}

\author{
Sylvie Rodrigues-Ferreira, Angie Molina, Clara Nahmias
}

\section{To cite this version:}

Sylvie Rodrigues-Ferreira, Angie Molina, Clara Nahmias. Microtubule-associated tumor suppressors as prognostic biomarkers in breast cancer. Breast Cancer Research and Treatment, 2020, 179, pp.267273. 10.1007/s10549-019-05463-x . hal-02411557

\section{HAL Id: hal-02411557 \\ https://hal-univ-tlse2.archives-ouvertes.fr/hal-02411557}

Submitted on 24 Nov 2020

HAL is a multi-disciplinary open access archive for the deposit and dissemination of scientific research documents, whether they are published or not. The documents may come from teaching and research institutions in France or abroad, or from public or private research centers.
L'archive ouverte pluridisciplinaire HAL, est destinée au dépôt et à la diffusion de documents scientifiques de niveau recherche, publiés ou non, émanant des établissements d'enseignement et de recherche français ou étrangers, des laboratoires publics ou privés. 


\section{Microtubule-associated tumor suppressors as prognostic biomarkers in breast cancer}

Sylvie Rodrigues-Ferreira ${ }^{1,2}$, Angie Molina ${ }^{1,3}$ and Clara Nahmias ${ }^{1 *}$.

1. INSERM U981, LabEx LERMIT, Université Paris Sud, Gustave Roussy Cancer Center, Department of Molecular Medicine, 94800 Villejuif, France.

2. Inovarion, 75014 Paris, France.

3. Present address : UMR 5547 CNRS/Université Paul Sabatier, Centre de Biologie du Développement, Centre de Biologie Intégrative, 31400 Toulouse, France.

\section{*Correspondence:}

Clara Nahmias, PhD., Inserm U981, Gustave Roussy Cancer Center, 114 rue Edouard Vaillant, 94800 Villejuif. Email: clara.nahmias@inserm.fr Tel : (+33) 682006933

Key words: ATIP3, Combinatorial expression, EB1, Microtubule-associated protein, Prognosis, Tumor suppressor 


\begin{abstract}
Breast cancer is the most common malignancy in women worldwide. Although important therapeutic progress was achieved over the past decade, this disease remains a public health problem. In the light of precision medicine, the identification of new prognostic biomarkers in breast cancer is urgently needed to stratify populations of patients with poor clinical outcome who may benefit from new personalized therapies. The microtubule cytoskeleton plays a pivotal role in essential cellular functions and is an interesting target for cancer therapy. Microtubule assembly and dynamics are regulated by a wide range of microtubule-associated proteins (MAPs), some of which have oncogenic or tumor suppressors effects in breast cancer. This review covers current knowledge on microtubule-associated tumor suppressors (MATS) in breast cancer and their potential value as prognostic biomarkers. We present recent studies showing that combinatorial expression of ATIP3 and EB1, two microtubule-associated biomarkers with tumor suppressor and oncogenic effects, respectively, improves breast cancer prognosis compared to each biomarker alone. These findings are discussed regarding the increasing complexity of protein networks composed of MAPs that coordinate microtubule dynamics and functions. Further studies are warranted to evaluate the prognostic value of combined expression of different MATS and their interacting partners in breast cancer.
\end{abstract}




\section{Introduction}

Breast cancer is a major cause of death in women worldwide. Clinical management of this heterogeneous disease relies on well-established clinico-pathological characteristics and molecular biomarkers, including estrogen and progesterone receptors as well as the HER2 oncogene [1]. The classification of breast tumors into distinct molecular subtypes (Luminal, HER2-positive and triple-negative) is of invaluable help in making clinical decisions. However, tumors from the same subtype still remain heterogeneous in terms of prognosis and response to therapy [2]. Over the past decade, the emergence of high-throughput techniques for molecular profiling and DNA sequencing of breast tumors has allowed extensive progress in the classification, prognosis and treatment of early and advanced breast cancer $[3,4]$. In the light of precision medicine, the continuously increasing accumulation of big data opens new avenues of investigation [5]. The identification of novel biomarkers enabling personalized therapeutic strategies for selected breast tumors has become a major issue [6]. An important point to reach is the ability to identify prognostic biomarkers to stratify populations of breast cancer patients at high risk to relapse and develop metastasis. Selecting these patients is a prerequisite to the development of targeted therapies.

The microtubule cytoskeleton is an essential cellular component that plays a key role in various biological processes such as cell division, polarity and migration, all of which are altered in cancer. Microtubules are polarized protofilaments composed of $\square \square$-tubulin heterodimers that are organized head-to-tail and grow from the minus to the plus end. These are highly dynamic structures, constantly switching between phases of polymerization (growth) and depolymerization (shrinkage) at their plus ends, a process called dynamic instability. Dynamic instability allows the microtubule cytoskeleton to explore the cytosol and rapidly reorganize in response to external cues to ensure appropriate cell function. Coordinated regulation of microtubule dynamics during mitosis and interphase permits mitotic spindle formation and orientation, chromosomes segregation towards cell poles during anaphase, cytoskeleton and cell shape remodeling, intracellular trafficking and signaling as well as cell migration and polarization. 
Microtubule assembly and dynamics are tightly regulated by a large number of microtubule-associated the network. A subset of MAPs, known as kinesins, function as molecular motors to ensure intracellular transport of proteins and organelles. Some MAPs localize along the microtubule lattice (structural MAPs) whereas others preferentially bind to microtubule plus ends (+TIPs) or minus ends (-TIPs) [7]. At the plus end, End-Binding proteins (EB1, EB2, EB3) play a major role as scaffolds to recruit a wide range of plus-end tracking proteins that contribute to the regulation of microtubule dynamics and targeting of organelles [7, 8]. Minus ends are occupied by large complexes of MAPs, also including EB1, that cooperate to regulate microtubule nucleation and dynamics [9].

Because they regulate the organization and function of the microtubule cytoskeleton in interphase and mitosis, MAPs can be considered as the "guardians" of cellular integrity. Alterations in the sequence or expression levels of these proteins may lead to cytoskeletal defects with major consequences on cancer initiation or progression. Indeed, a number of MAPs have been described as oncogenes or tumor suppressors whose deregulation has a major impact on cancer aggressiveness and clinical outcome for the patients. In this review we will focus on microtubule-associated proteins with tumor suppressor effects (MATS) in breast cancer.

\section{A family of microtubule-associated tumor suppressors (MATS) in breast cancer}

A total of 10 MAPs with tumor suppressive functions have been identified in breast cancer. These proteins include Adenomatous Polyposis Coli (APC), Microtubule-associated tumor suppressor 1 (MTUS1) protein ATIP3, Breast Cancer 1 (BRCA1), Cylindromatosis tumor suppressor (CYLD), Fragile Histidine Triad (FHIT), Leucine Zipper putative Tumor Suppressor 1 (LZTS1), Neurofibromatosis 2 (NF2) protein Merlin, Navigator-3 (NAV3), RAS Association domain Family 1A (RASSF1A), and Von Hippel-Lindau (VHL) (Table 1).

BRCA1 is known as a master tumor suppressor in breast cancer. Interestingly, besides its key role in DNA repair, BRCA1 has also been shown to reduce microtubule dynamics [10]. BRCA1 was found to localize on the mitotic spindle and at the centrosome where it interacts with $\square$-tubulin, a centrosomal protein crucial for microtubule nucleation $[11,12]$. APC, another master tumor suppressor, also localizes 
at the centrosome [13], a localization shared by other MATS such as ATIP3 [14], RASSF1A [15, 16] and VHL [17]. Of note, APC was the first protein shown to interact with microtubule end-binding protein EB1 [18] via a canonical SxIP motif [7, 19, 20]. APC was thus identified as a plus-end tracking protein [20], like NAV3 [21] and CYLD [22] that bind EB1 through SxIP and CAP-Gly motifs, respectively. In addition, most MATS were shown to decorate the microtubule lattice in interphase and/or the mitotic spindle during mitosis [14-17, 23-26] (Table 1).

The majority of MATS are microtubule stabilizers that regulate different parameters of microtubule dynamics. Indeed, ATIP3 [27], BRCA1 [10], Merlin [28] and RASSF1A [15, 16] decrease microtubule growth rate whereas APC [20] and VHL [17] protect MTs from depolymerization. FHIT [29] and LZTS1 [25] promote MT assembly. NAV3 [21] and CYLD [22] both stabilize microtubules and promote their assembly (Table 1). Considering that these proteins are often co-localized on microtubules and that they all contribute to the regulation of microtubule organization and dynamics, it will be of interest to evaluate whether different MATS may have compensatory effects - in which the loss of one of these proteins could be balanced by another - or cooperative effects - in which expression of two or more proteins is necessary for microtubule regulation.

In breast cancer, MATS have been shown to be downregulated in 30 to $80 \%$ of tumor samples compared to normal adjacent tissues [14, 21, 30-38] (Table 2). Except for BRCA1 and APC, MATS genes are not heavily mutated in primary breast tumors. Their reduced expression level in breast cancer results from promoter hypermethylation for APC, FHIT, LZTS1 and RASSF1A genes [36, 39-41] and loss of heterozygosity for APC, BRCA1 and FHIT [39, 40, 42]. Other mechanisms involving microRNAmediated targeting of CYLD, LZTS1 and VHL genes in breast cancer have been more recently reported [43-45]. NF2 has been shown to be down-regulated at the post-translational level in advanced breast cancer by proteasome-dependent degradation [35]. The mechanisms responsible for down-regulation of MTUS1 and NAV3 genes in breast cancer still remain to be determined.

Interestingly, low levels of MTUS1/ATIP3 [14], CYLD [32], FHIT [40], NAV3 [21] and RASSF1A [36] are significantly associated with ER-negative, highly proliferative and/or high-grade breast tumors, indicating that loss of MATS in breast cancer is associated with tumor aggressiveness. Furthermore, 
when considering MATS level and patient outcomes, studies have shown that for the majority of MATS, [21, 27, 32, 34, 37, 46-48] (Table 2). Thus, MATS may represent useful prognostic biomarkers in breast cancer.

\section{Prognostic value of ATIP3/EB1 combination : two biomarkers are better than one}

The ATIP3 protein is an interesting example of a MATS with prognostic value in breast cancer. ATIP3 belongs to a family of proteins encoded by alternative splicing of the MTUSI gene located at chromosome 8p22 $[49,50]$. This protein is expressed in epithelial cells of the mammary gland in normal breast tissue and is markedly down-regulated both at the mRNA and protein level in half of invasive breast tumors [14]. Low levels of ATIP3 are associated with tumor aggressiveness, metastatic properties and reduced clinical outcome for breast cancer patients. Furthermore, re-expression of ATIP3 into breast cancer cell lines significantly reduces cell proliferation, polarity and migration, as well as tumor growth and metastasis in experimental mouse models [14, 27], highlighting ATIP3 as a prognostic biomarker and a potent anti-cancer and anti-metastasis protein.

As mentioned above, ATIP3 localizes at the centrosome and along the microtubule lattice in interphase and decorates the mitotic spindle and spindle poles during mitosis [14]. Proximity mapping and functional analysis of the human centrosome-cilium interactome also revealed that ATIP3/MTUS1 belongs to a centrosomal protein network that regulates centrosomal functions [51]. Like most other MATS (Table 1), ATIP3 stabilizes microtubules. Its depletion significantly increases microtubule dynamics at the plus end by increasing microtubule growth and growth rate and reducing the time spent in pause [27]. At the molecular level, ATIP3 directly interacts with end-binding protein EB1 via a proline-rich and basic SxIP-like motif (RPLPLP) [52]. ATIP3-EB1 interaction takes place in the cytosol, is independent of microtubules, and impairs EB1 binding and turnover at the plus ends [52]. Strikingly, while almost all SxIP-containing EB1-binding proteins are +TIPs that localize at the plus end [7, 8, 19], ATIP3 is a unique example of SxIP-containing protein that does not accumulate at the plus ends and rather acts as an endogenous antagonist of EB1 [53]. 
In breast cancer, EB1 levels were found elevated at the mRNA and protein levels compared to normal

tissue $[54,55]$. Furthermore, EB1 (but not EB2 or EB3) was identified as a prognostic biomarker whose high expression in breast tumors associates with tumor malignancy, high histological grade and reduced overall survival of the patients [55]. The observation that ATIP3 negatively regulates EB1 functions launched further studies to investigate the clinical relevance of ATIP3-EB1 interaction for breast cancer patients. Results showed that in high-EB1 expressing breast tumors, ATIP3 deficiency results in increased tumor aggressiveness, with subsequent consequences on patient prognosis (Figure 1). Furthermore, analyzing combinatorial expression of ATIP3 and EB1 in five independent cohorts of patients significantly improved breast cancer diagnosis and prognosis compared to each biomarker alone [55]. Importantly, these studies allowed to identify a population of breast cancer patients of worse clinical outcome expressing high EB1 and low-ATIP3 levels. This population of patients, that represents $30 \%$ of breast cancer cases, may be eligible to molecular therapies aimed at restoring or mimicking ATIP3-EB1 interaction. Integrative approaches have recently been described for the discovery of small molecule modulators of EB1 binding to SxIP motifs [56]. Such strategies may open interesting perspectives towards the development of personalized treatments to compensate for ATIP3 loss in a selected population of patients with high-EB1/low-ATIP3 expressing breast tumors.

Notably, other MATS such as APC, CYLD and NAV3 also interact with EB1 (Table 1). However, in contrast to ATIP3, these MATS are +TIPs that accumulate at the microtubule plus ends. Furthermore, APC and CYLD have been shown to cooperate with EB1 rather than antagonize its effects on cell migration [57-59]. These observations may suggest that loss of APC or CYLD in high-EB1 expressing breast tumors may impact tumor aggressiveness and clinical outcome for the patients. It will be of interest to investigate whether, similar to the ATIP3-EB1 couple, combinatorial expression of CYLDEB1 and/or APC-EB1 may improve breast cancer prognosis.

\section{Concluding remarks}

In conclusion, among the large number of MAPs that control the microtubule network in interphase and mitosis, only few have been identified as bona fide microtubule-associated tumor suppressors (MATS) in breast cancer. Their deficiency in breast tumors is associated with poor prognosis of the patients, 
highlighting their potential value as biomarkers. Pioneer studies of ATIP3, a MATS that binds to EB1

and antagonizes its oncogenic effects in breast cancer, provide the first proof-of-concept that combinatorial expression of two biomarkers with opposite actions on microtubules improves breast cancer prognosis compared to each biomarker alone.

Several MATS do co-localize inside the cell, and some of them have been shown to act in concert. This raises the possibility that combinatorial expression of those microtubule-associated tumor suppressors may have improved value as biomarkers for the stratification of breast cancer patients in the context of personalized medicine. These data are particularly important considering increasing evidence that large numbers of MAPs are engaged into protein networks whose coordinated actions allow fine tuning of microtubule dynamics and assembly. In this line, the concomitant loss of BRCA1 and FHIT in sporadic breast cancer has been associated with reduced patients survival, suggesting that combination of these two MATS may be used as a marker to identify a subpopulation of breast tumor with poor prognosis [60]. Further studies are warranted to evaluate the prognostic value of combined alterations of two or more MATS, together with other MAPs and their binding partners in breast cancer. The high complexity of MAPs networks suggests a novel paradigm for future discovery of a new generation of complex prognostic biomarkers in breast cancer.

Acknowledgements : This work has been funded by Gustave Roussy Cancer Center, the ANR grant MMO ANR-10-IBHU-0001, the Comité Ile-de-France of the Ligue Nationale contre le Cancer, the Ligue contre le Cancer 94/Val-de-Marne, the Entreprises contre le cancer (GEFLUC) Ile-de-France, the Fondation ARC pour la recherche contre le cancer, the CNRS, the INSERM, the Foundation Janssen Horizon, the Fonds de Dotation Agnès b., the association Odyssea and Prolific.

\section{Conflict of interests :}

Authors declare that they have no conflict of interests. 


\section{References}

1. Harbeck N, Gnant M (2017) Breast cancer. Lancet 389:1134-1150.

2. Falco M, Palma G, Rea D, De Biase D, Scala S, D'Aiuto M et al (2016) Tumour biomarkers: homeostasis as a novel prognostic indicator. Open Biol 6(12) pii: 160254.

3. André F, Bachelot T, Commo F, Campone M, Arnedos M, Dieras V et al (2014) Comparative genomic hybridisation array and DNA sequencing to direct treatment of metastatic breast cancer: a multicentre, prospective trial (SAFIR01/UNICANCER). Lancet Oncol 15: 267-274.

4. Bertucci F, Ng CKY, Patsouris A, Droin N, Piscuoglio S, Carbuccia N et al (2019) Genomic characterization of metastatic breast cancers. Nature 569:560-564.

5. Low SK, Zembutsu H, Nakamura Y (2018) Breast cancer: The translation of big genomic data to cancer precision medicine. Cancer Sci 109:497-506.

6. Bettaieb A, Paul C, Plenchette S, Shan J, Chouchane L, Ghiringhelli F (2017) Precision medicine in breast cancer: reality or utopia? J Transl Med 15:139.

7. Akhmanova A, Steinmetz MO (2015) Control of microtubule organization and dynamics: two ends in the limelight. Nat Rev Mol Cell Biol 16:711-726.

8. Jiang K, Toedt G, Montenegro Gouveia S, Davey NE, Hua S, van der Vaart B et al (2012) A Proteome-wide screen for mammalian SxIP motif-containing microtubule plus-end tracking proteins. Curr Biol 22:1800-1807.

9. Martin M, Akhmanova A (2018) Coming into Focus: Mechanisms of Microtubule Minus-End Organization. Trends Cell Biol 28:574-588.

10. Sung M, Giannakakou P (2014) BRCA1 regulates microtubule dynamics and taxane-induced apoptotic cell signaling. Oncogene 33:1418-1428.

11. Hsu LC, White RL (1998) BRCA1 is associated with the centrosome during mitosis. Proc Natl Acad Sci U S A 95:12983-12988.

12. Lotti LV, Ottini L, D'Amico C, Gradini R, Cama A, Belleudi F et al (2002) Subcellular localization of the BRCA1 gene product in mitotic cells. Genes Chromosomes Cancer 35:193-203.

13. Louie RK, Bahmanyar S, Siemers KA, Votin V, Chang P, Stearns T et al (2004) Adenomatous polyposis coli and EB1 localize in close proximity of the mother centriole and EB1 is a functional component of centrosomes. J Cell Sci 117(Pt 7):1117-1128.

14. Rodrigues-Ferreira S, Di Tommaso A, Dimitrov A, Cazaubon S, Gruel N, Colasson H et al (2009) 8p22 MTUS1 gene product ATIP3 is a novel anti-mitotic protein underexpressed in invasive breast carcinoma of poor prognosis. PLoS One 4(10): 7239.

15. Liu L, Tommasi S, Lee DH, Dammann R, Pfeifer GP (2003) Control of microtubule stability by the RASSF1A tumor suppressor. Oncogene 22:8125-8136.

16. Rong R, Jin W, Zhang J, Sheikh MS, Huang Y (2004) Tumor suppressor RASSF1A is a microtubule-binding protein that stabilizes microtubules and induces $\mathrm{G} 2 / \mathrm{M}$ arrest. Oncogene 23:8216-8230.

17. Thoma CR, Toso A, Gutbrodt KL, Reggi SP, Frew IJ, Schraml P et al (2009) VHL loss causes spindle misorientation and chromosome instability. Nat Cell Biol 11:994-1001. 
18. Morrison EE (2009) The APC-EB1 interaction. Adv Exp Med Biol 656:41-50.

19. Honnappa S, Gouveia SM, Weisbrich A, Damberger FF, Bhavesh NS, Jawhari H et al (2009) An EB1-binding motif acts as a microtubule tip localization signal. Cell 138:366-376.

20. Slep KC, Rogers SL, Elliott SL, Ohkura H, Kolodziej PA, Vale RD (2005) Structural determinants for EB1-mediated recruitment of APC and spectraplakins to the microtubule plus end. $J$ Cell Biol 168:587-598.

21. Cohen-Dvashi H, Ben-Chetrit N, Russell R, Carvalho S, Lauriola M, Nisani S et al (2015) Navigator3 , a modulator of cell migration, may act as a suppressor of breast cancer progression. EMBO Mol Med 7:299-314.

22. Gao J, Huo L, Sun X, Liu M, Li D, Dong JT et al (2008) The tumor suppressor CYLD regulates microtubule dynamics and plays a role in cell migration. J Biol Chem 283:8802-8809.

23. Munemitsu S, Souza B, Müller O, Albert I, Rubinfeld B, Polakis P (1994) The APC gene product associates with microtubules in vivo and promotes their assembly in vitro. Cancer Res 54:3676-3681.

24. Stegmeier F, Sowa ME, Nalepa G, Gygi SP, Harper JW, Elledge SJ (2007) The tumor suppressor CYLD regulates entry into mitosis. Proc Natl Acad Sci U S A 104:8869-8874.

25. Ishii H, Vecchione A, Murakumo Y, Baldassarre G, Numata S, Trapasso F et al (2001) FEZ1/LZTS1 gene at 8p22 suppresses cancer cell growth and regulates mitosis. Proc Natl Acad Sci U $S$ A 98:10374-10379.

26. Muranen T, Grönholm M, Lampin A, Lallemand D, Zhao F, Giovannini M et al (2007) The tumor suppressor merlin interacts with microtubules and modulates Schwann cell microtubule cytoskeleton. Hum Mol Genet 16:1742-1751.

27. Molina A, Velot L, Ghouinem L, Abdelkarim M, Bouchet BP, Luissint AC (2013) ATIP3, a novel prognostic marker of breast cancer patient survival, limits cancer cell migration and slows metastatic progression by regulating microtubule dynamics. Cancer Res 73:2905-2915.

28. Smole Z, Thoma CR, Applegate, KT, Duda M, Gutbrodt KL, Danuser G et al (2014) Tumor suppressor NF2/Merlin is a microtubule stabilizer. Cancer Res 74:353-362.

29. Chaudhuri AR, Khan IA, Prasad V, Robinson AK, Ludueña, RF, Barnes LD (1999) The tumor suppressor protein Fhit. A novel interaction with tubulin. J Biol Chem 274:24378-24382.

30. Ho KY, Kalle WH, Lo TH, Lam WY, Tang CM (1999) Reduced expression of APC and DCC gene protein in breast cancer. Histopathology 35:249-256.

31. Rakha EA, El-Sheikh SE, Kandil MA, El-Sayed ME, Green AR, Ellis IO (2008) Expression of BRCA1 protein in breast cancer and its prognostic significance. Hum Pathol 39:857-865.

32. Hayashi M, Jono H, Shinriki S, Nakamura T, Guo J, Sueta A et al (2014) Clinical significance of CYLD downregulation in breast cancer. Breast Cancer Res Treat 143:447-457.

33. Campiglio M, Pekarsky Y, Menard S, Tagliabue E, Pilotti S, Croce CM (1999) FHIT loss of function in human primary breast cancer correlates with advanced stage of the disease. Cancer Res 59:38663869.

34. Lovat F, Ishii H, Schiappacassi M, Fassan M, Barbareschi M, Galligioni E et al (2014) LZTS1 downregulation confers paclitaxel resistance and is associated with worse prognosis in breast cancer. Oncotarget 5:970-977. 
35. Morrow KA, Das S, Metge BJ, Ye K, Mulekar MS, Tucker JA et al (2011) Loss of tumor suppressor Merlin in advanced breast cancer is due to post-translational regulation. J Biol Chem 286:40376-40385.

36. Hagrass HA, Pasha HF, Shaheen MA, Abdel Bary EH, Kassem R (2014) Methylation status and protein expression of RASSF1A in breast cancer patients. Mol Biol Rep 41:57-65.

37. Zia MK, Rmali KA, Watkins G, Mansel RE, Jiang WG (2007) The expression of the von HippelLindau gene product and its impact on invasiveness of human breast cancer cells. Int J Mol Med 20:605611.

38. Hu D, Zhou Z, Davidson NE, Huang Y, Wan Y (2012) Novel insight into KLF4 proteolytic regulation in estrogen receptor signaling and breast carcinogenesis. J Biol Chem 287: 13584-13597.

39. Virmani AK, Rathi A, Sathyanarayana UG, Padar A, Huang CX, Cunnigham HT et al (2001) Aberrant methylation of the adenomatous polyposis coli (APC) gene promoter 1A in breast and lung carcinomas. Clin Cancer Res 7:1998-2004.

40. Yang Q, Nakamura M, Nakamura Y, Yoshimura G, Suzuma T, Umemura T et al (2002) Two-hit inactivation of FHIT by loss of heterozygosity and hypermethylation in breast cancer. Clin Cancer Res $8: 2890-2893$.

41. Chen L, Zhu Z, Sun X, Dong XY, Wei J, Gu F et al (2009) Down-regulation of tumor suppressor gene FEZ1/LZTS1 in breast carcinoma involves promoter methylation and associates with metastasis. Breast Cancer Res Treat 116:471-478.

42. Rosen EM, Fan S, Pestell RG, Goldberg ID (2003) BRCA1 gene in breast cancer. J Cell Physiol 196:19-41.

43. Kong W, He L, Richards EJ, Challa S, Xu CX, Permuth-Wey J et al (2014) Upregulation of miRNA-155 promotes tumour angiogenesis by targeting VHL and is associated with poor prognosis and triple-negative breast cancer. Oncogene 33:679-689.

44. Song H, Li D, Wu T, Xie D, Hua K, Hu J, et al (2018) MicroRNA-301b promotes cell proliferation and apoptosis resistance in triple-negative breast cancer by targeting CYLD. BMB Rep 51:602-607.

45. Hou X, Niu Z, Liu L, Guo Q, Li H, Yang X et al (2019) miR-1207-5p regulates the sensitivity of triple-negative breast cancer cells to Taxol treatment via the suppression of LZTS1 expression. Oncol Lett 17:990-998.

46. Huszno J, Kołosza Z, Grzybowska E (2019) BRCA1 mutation in breast cancer patients: Analysis of prognostic factors and survival. Oncol Lett 17:1986-1995.

47. Ginestier C, Bardou VJ, Popovici C, Charafe-Jauffret E, Bertucci F, Geneix J et al (2003) Loss of FHIT protein expression is a marker of adverse evolution in good prognosis localized breast cancer. Int $J$ Cancer 107:854-862.

48. Martins AT, Monteiro P, Ramalho-Carvalho J, Costa VL, Dinis-Ribeiro M, Leal C et al (2011) High RASSF1A promoter methylation levels are predictive of poor prognosis in fine-needle aspirate washings of breast cancer lesions. Breast Cancer Res Treat 129:1-9. 
49. Di Benedetto M, Bièche I, Deshayes F, Vacher S, Nouet S, Collura V et al (2006) Structural organization and expression of human MTUS1, a candidate 8p22 tumor suppressor gene encoding a family of angiotensin II AT2 receptor-interacting proteins, ATIP. Gene 380:127-136.

50. Rodrigues-Ferreira S, Nahmias C (2010) An ATIPical family of angiotensin II AT2 receptorinteracting proteins. Trends Endocrinol Metab 21:684-690.

51. Gupta GD, Coyaud É, Gonçalves J, Mojarad A, Liu Y, Wu Q et al (2015) Dynamic protein interaction landscape of the human centrosome-cilium interface. Cell 163:1484-1499.

52. Velot L, Molina A, Rodrigues-Ferreira S, Nehlig A, Bouchet BP, Morel M et al (2015) Negative regulation of EB1 turnover at microtubule plus ends by interaction with microtubule-associated protein ATIP3, Oncotarget 6:43557-43570.

53. Nehlig A, Molina A, Rodrigues-Ferreira S, Honoré S, Nahmias C (2017) Regulation of end-binding protein EB1 in the control of microtubule dynamics. Cell Mol Life Sci 74 :2381-2393.

54. Dong X, Liu F, Sun L, Liu M, Li D, Su D et al (2010) Oncogenic function of microtubule endbinding protein 1 in breast cancer. J Pathol 220:361-369.

55. Rodrigues-Ferreira S, Nehlig A, Monchecourt C, Nasr S, Fuhrmann L, Lacroix-Triki M et al (2019) Combinatorial expression of microtubule-associated EB1 and ATIP3 biomarkers improves breast cancer prognosis. Breast Cancer Res Treat 173:573-583.

56. Almeida TB, Carnell AJ, Barsukov IL, Berry NG (2017) Targeting SxIP-EB1 interaction: an integrated approach to the discovery of small molecule modulators of dynamic binding sites. Sci Rep 7:15533.

57. Wen Y, Eng CH, Schmoranzer J, Cabrera-Poch N, Morris EJ, Chen M et al (2004) EB1 and APC bind to mDia to stabilize microtubules downstream of Rho and promote cell migration. Nat Cell Biol 6:820-830.

58. Green RA, Wollman R, Kaplan KB (2005) APC and EB1 function together in mitosis to regulate spindle dynamics and chromosome alignment. Mol Biol Cell 16:4609-4622.

59. Li D, Gao J, Yang Y, Sun L, Suo S, Luo Y et al (2014) CYLD coordinates with EB1 to regulate microtubule dynamics and cell migration. Cell Cycle 13:974-983.

60. Silva Soares EW, de Lima Santos SC, Bueno AG, Cavalli IJ, Cavalli LR, Fouto Matias JE et al (2010) Concomitant loss of heterozygosity at the BRCA1 and FHIT genes as a prognostic factor in sporadic breast cancer. Cancer Genet Cytogenet 199:24-30. 


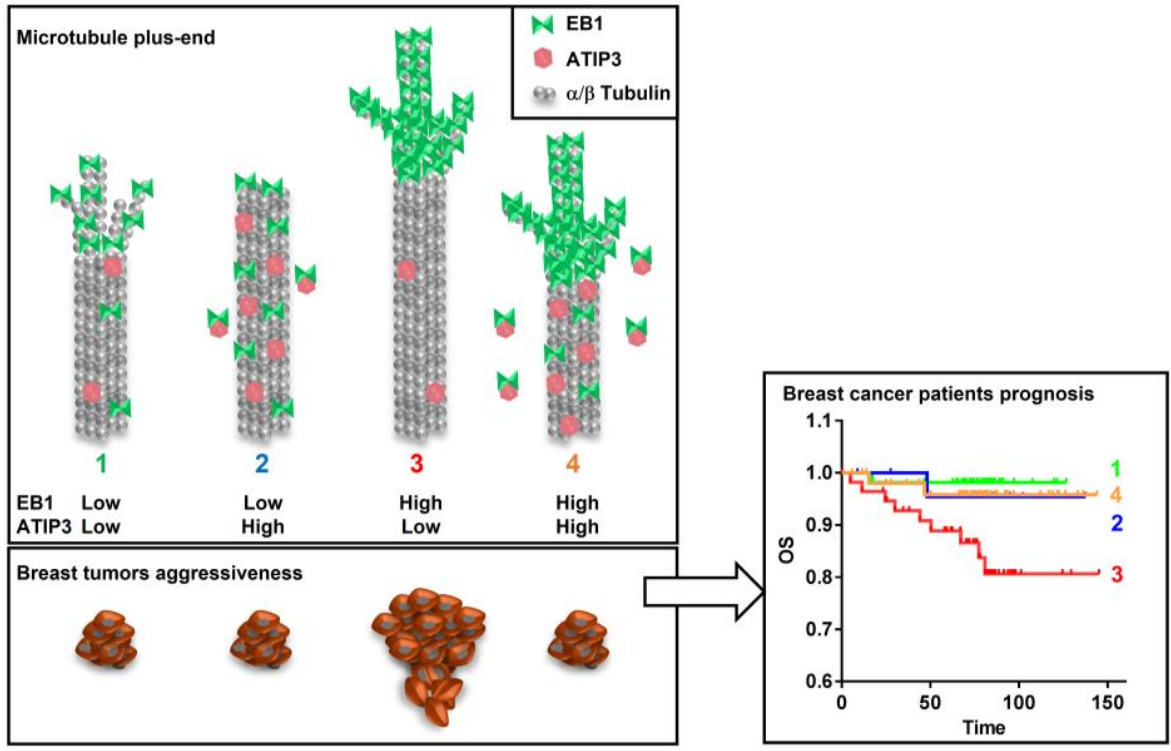

Figure 1

\section{Legend to Figure 1.}

Two biomarkers are better than one. Consequences of combinatorial expression of EB1 and ATIP3 on microtubule dynamics at the plus end (upper panel), breast cancer aggressiveness (lower panel) and overall survival of breast cancer patients (right panel). Tumors were classified according to combined EB1-ATIP3 expression as group 1 (EB1-low and ATIP3-low), group 2 (EB1-low and ATIP3-high), group 3 (EB1-high and ATIP3-low) and group 4 (EB1-high and ATIP3-high). Kaplan-Meier representation on the right indicates that breast tumors from group 3 are of worse prognosis compared to all other groups $(\mathrm{p}<0.05)$. 


\begin{tabular}{|c|c|c|c|c|}
\hline MATS & Name & Localization & Effect on MT & $\begin{array}{c}\text { EB1 } \\
\text { interaction }\end{array}$ \\
\hline APC & $\begin{array}{l}\text { Adenomatous Polyposis } \\
\text { Coli }\end{array}$ & $\begin{array}{l}\text { MT network, centrosome, } \\
\text { MT plus ends }[13,23]\end{array}$ & Stabilization [20] & SxIP $[19,20]$ \\
\hline ATIP3 & $\begin{array}{c}\text { Microtubule associated } \\
\text { tumor suppressor MTUS1 } \\
\text { /ATIP3 }\end{array}$ & $\begin{array}{l}\text { MT network, centrosome, } \\
\text { mitotic spindle }[14,27]\end{array}$ & Stabilization [27] & RPLP [52] \\
\hline BRCA1 & Breast Cancer 1 & $\begin{array}{l}\text { Centrosome, mitotic } \\
\text { spindle }[11,12]\end{array}$ & Stabilization [10] & no \\
\hline CYLD & $\begin{array}{l}\text { Cylindromatosis tumor } \\
\text { suppressor }\end{array}$ & $\begin{array}{l}\text { MT network, MT plus end, } \\
\text { midbody }[22,24]\end{array}$ & $\begin{array}{l}\text { Stabilization and } \\
\text { assembly [22] }\end{array}$ & CAP-Gly [59] \\
\hline FHIT & Fragile Histidine Triad & nd & $\begin{array}{l}\text { Tubulin interaction, } \\
\text { MT assembly [29] }\end{array}$ & nd \\
\hline LZTS1 & $\begin{array}{l}\text { Leucine Zipper putative } \\
\text { Tumor Suppressor } 1\end{array}$ & MT network [25] & MT assembly [25] & nd \\
\hline Merlin/NF2 & $\begin{array}{c}\text { Neurofibromatosis } 2 \text { (NF2) } \\
\text { protein Merlin }\end{array}$ & $\begin{array}{l}\text { MT network, mitotic } \\
\text { spindle [26] }\end{array}$ & Stabilization [28] & nd \\
\hline NAV3 & Navigator-3 & MT plus end [21] & Stabilization [21] & SxIP [8] \\
\hline RASSF1A & $\begin{array}{c}\text { RAS Association domain } \\
\text { Family 1A }\end{array}$ & $\begin{array}{l}\text { MT network, centrosome, } \\
\text { mitotic spindle }[15,16]\end{array}$ & Stabilization $[15,16]$ & nd \\
\hline VHL & Von Hippel-Lindau & $\begin{array}{l}\text { MT network, centrosome, } \\
\text { mitotic spindle [17] }\end{array}$ & Stabilization [17] & nd \\
\hline
\end{tabular}

Table 1. Microtubule-Associated Tumor Suppressors (MATS) properties related to microtubules.

Protein localization, effect on microtubule assembly and stability, and ability to interact with EB1, are presented. nd : not determined 


\begin{tabular}{|c|c|c|c|}
\hline MATS & $\begin{array}{l}\text { Reduced Expression in } \\
\text { breast cancer }\end{array}$ & Inactivated by & Prognostic biomarker \\
\hline APC & $40,7 \%[30]$ & LOH - Promoter hypermethylation [39] & nd \\
\hline ATIP3 & $48 \%[14]$ & nd & {$[27]$} \\
\hline BRCA1 & $54 \%[31]$ & $\mathrm{LOH}[42]$ & {$[46]$} \\
\hline CYLD & $29,9 \%[32]$ & MicroRNA targeting [44] & {$[34]$} \\
\hline FHIT & $69 \%[33]$ & LOH - Promoter hypermethylation [40] & [47] \\
\hline LZTS1 & $43,7 \%[34]$ & $\begin{array}{l}\text { Promoter hypermetylation [41] } \\
\text { MicroRNA targeting [45] }\end{array}$ & {$[34]$} \\
\hline Merlin/NF2 & $75 \%[35]$ & *Proteasomal degradation [35] & nd \\
\hline NAV3 & $37-79,3 \%[21]$ & nd & {$[21]$} \\
\hline RASSF1A & $53,3 \%[36]$ & Promoter hypermethylation [36] & [48] \\
\hline VHL & $\mathrm{nc}[37,38]$ & MicroRNA targeting [43] & [37] \\
\hline
\end{tabular}

\section{Table 2. Microtubule-Associated Tumor Suppressors (MATS) in breast cancer.}

The percentage of primary breast tumors with reduced expression of MATS, mechanisms of gene inactivation, and prognostic value of MATS in breast cancer patients, are presented. LOH: Loss Of Heterozygosity; nc : not calculated; nd : not determined. A star indicates down-regulation at the posttranslational level. 